\title{
A STUDY OF THE MORPHOLOGY AND MORPHOMETRY OF THE JUGULAR FORAM EN OF THE HUMAN DRY SKULLS
}

\author{
M. Anuradha *1, S. Chitra ${ }^{2}$. \\ ${ }^{* 1}$ Assistant Professor, Department of Anatomy, Stanley M edical College, Chennai, Tamilnadu, \\ India. \\ ${ }^{2}$ Professor and HOD, ${ }^{2}$ Department of Anatomy, Stanley Medical College, Chennai, Tamilnadu, \\ India.
}

\section{ABSTRACT}

Background: The jugular foramen, the bony opening is situated in the base of skull. It allows passage of important nervous and vascular elements, such as the glossopharyngeal, vagus, accessory nerve and the internal jugular vein. M ost of the approaches for skull base surgeries are designed to drill the bone around jugular foramen for proper exposure. Therefore the knowledge of anatomical variations of jugular foramen is important.

Material and Methods: A total of 100 jugular foramina were examined from 50 adult dry skullsin the department of anatomy, Stanley M edical College, Chennai, Tamilnadu, India.

Results: The mean anteroposterior diameter of the jugular foramen on the right and left were $12.11 \mathrm{~mm}$ and $11.09 \mathrm{~mm}$; the mediolateral diameter were $15.06 \mathrm{~mm}$ and $14.02 \mathrm{~mm}$ on the right and left respectively. In $63 \%$ of cases the right foramina were larger than the left, in $12 \%$ of cases the left foramina were larger than the right and in $25 \%$ cases they were equal in size on both sides. The septation in the jugular foramina on the right and left side was $35 \%$ and $31 \%$ respectively. Complete septation was present in $17 \%$ on the right side and $17 \%$ on the left side. Partial septation was present in $17 \%$ and $12 \%$ on the right and left side respectively.

Conclusion: Glomus tumour, schwannomas, metastatic lesions and infiltrating inflammatory processes can also occur in the jugular foramen. Hence, a detailed knowledge of the jugular foramen is important for neurosurgeons and radiologists dealing with space occupying lesions in jugular foramen.

KEY WORDS: Jugular Foramen, Skull, Septation, Glomus Tumour, Schwannomas.

Address for Correspondence: Dr. M .Anuradha, Assistant Professor, Department of Anatomy, Stanley Medical College, Chennai, Tamilnadu, India. E-Mail: dranurac@yahoo.com

\begin{tabular}{|c|c|c|}
\hline \multicolumn{3}{|c|}{ Access this Article online } \\
\hline \multirow{3}{*}{$\begin{array}{c}\text { Quick Response code } \\
\text { Dol: } 10.16965 / \text { ijar.2017.224 }\end{array}$} & \multicolumn{2}{|c|}{$\begin{array}{c}\text { Web site: International Journal of Anatomy and Research } \\
\text { ISSN 2321-4287 } \\
\text { www.ijmhr.org/ijar.htm }\end{array}$} \\
\hline & $\begin{array}{l}\text { Received: } 17 \text { Apr } 2017 \\
\text { Peer Review: } 18 \text { Apr } 2017 \\
\text { Revised: None }\end{array}$ & $\begin{array}{l}\text { Accepted: } 23 \text { M ay } 2017 \\
\text { Published (O): } 30 \text { Jun } 2017 \\
\text { Published (P): } 30 \text { Jun } 2017\end{array}$ \\
\hline & & \\
\hline
\end{tabular}

\section{INTRODUCTION}

Jugular foramen is one of the important foramina in posterior part of the base of the skull. It lies between the lateral part of occipital bone and the petrous part of temporal bone [1]. Jugular foramen is separated anteriorly from the inferior carotid opening by a crest, the carotico jugular spine. Laterally related to the medial aspect of the styloid sheath and separated from the hypoglossal canal by a thin osseous bar of bone [2]. It allows passage of important nervous and vascular elements, such as the glossopharyngeal, vagus, accessory nerves, internal jugular vein, two dural sinuses, and the meningeal branches of the occipital and ascending pharyngeal arteries [3].

Glomic tumors, schwannomas, metastatic lesions and infiltrating inflammatory processes 
are associated with this foramen, which can account for injuries of related structures. Surgical resection is the treatment of choice in the majority of these cases. Tumors involving the jugular foramen and adjacent structures require a microsurgical approach [4]. Most of the surgical procedures are designed to drill the bone around the jugular foramen for proper exposure [5-7]. Also the neoplastic pathologies tend to alter the normal anatomy of jugular foramen by invasion, erosion or expansion [8,9]. The jugular foramen varies in shape and size from side to side in the same cranium, and in different crania, racial groups and sexes. Thus the knowledge of relevant anatomical details regarding morphology and morphometry of jugular foramen in the regional population would be of great help to surgeons while approaching these lesions.

\section{MATERIALS AND METHODS}

A total of 100 jugular foramina were examined from 50 adult dry skulls. The skulls were obtained from the osteological collection of the Department of Anatomy, Stanley Medical College, Chennai, Tamilnadu. M easurements were taken bilaterally with the help of digital caliper in millimetres.

The jugular foramen is evaluated under the following headings

\section{Anteroposterior diameter of jugular foramen}

2. M ediolateral diameter of jugular foramen

3. Comparison of size between the right and left foramina of same skull

4. Presence of septation in the jugular foramen

5. Nature of the septation in the jugular foramen.

The anteroposterior diameter was recorded by calculating the distance between the anterior most and the posterior most point in the jugular foramen. The mediolateral diameter was recorded by calculating the distance between the medial most and the lateral most point in the jugular foramen. The value was taken both on the right and left side. The size between the right and left foramina was calculated relatively. The septation on both sides of the foramina was recorded by naked eye examination.

\section{RESULTS}

Fig. 1: M easuring Anteroposterior diameter in the jugular foramen.

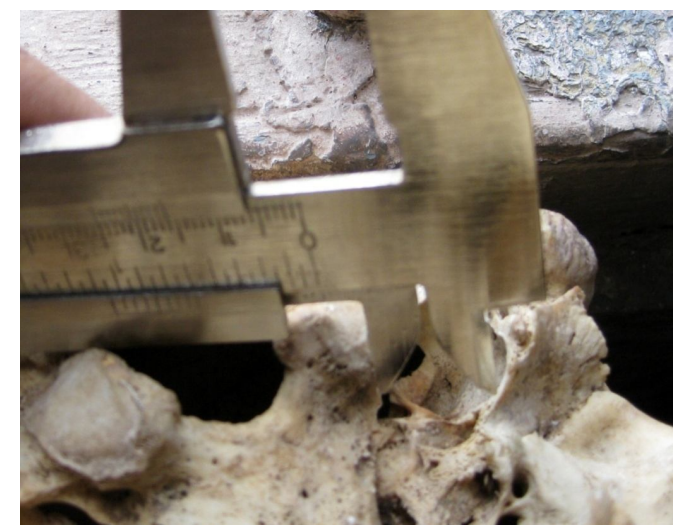

Fig. 2: Measuring Mediolateral diameter in the jugular foramen.

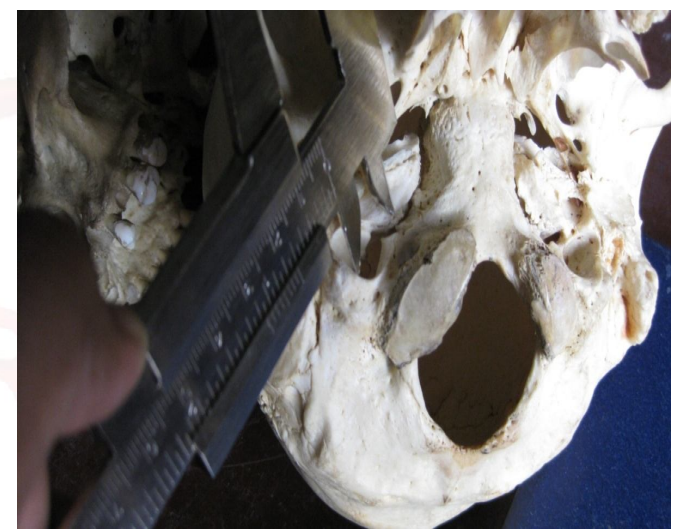

Fig. 3: Comparing the size of the two foramina in same skull.

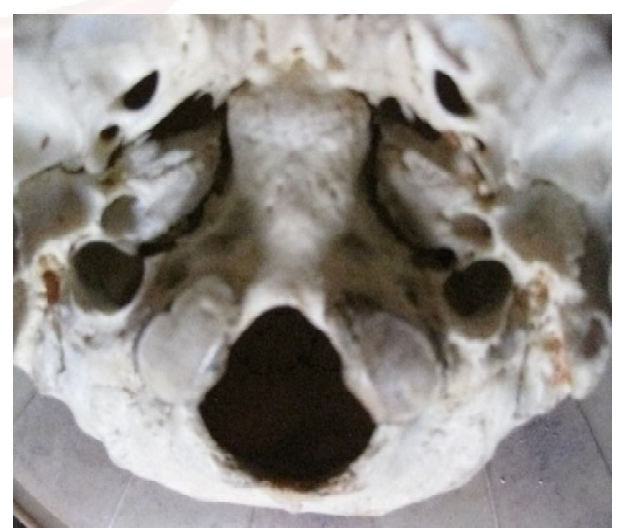

Fig. 4: Septation in the jugular foramen.

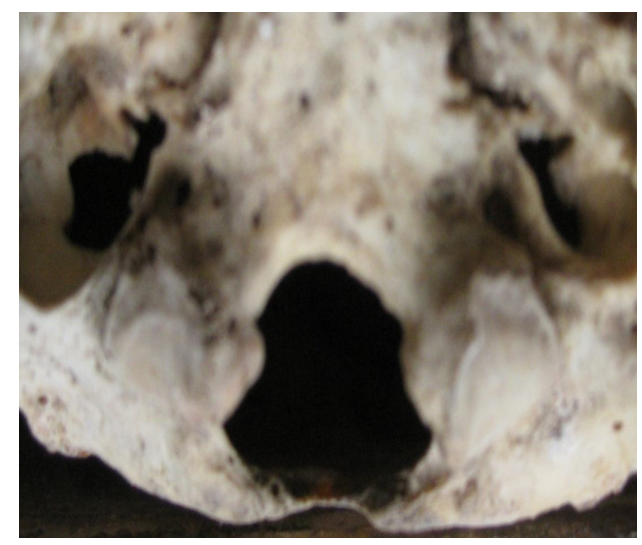


Fig. 5: Septation in the jugular foramen.

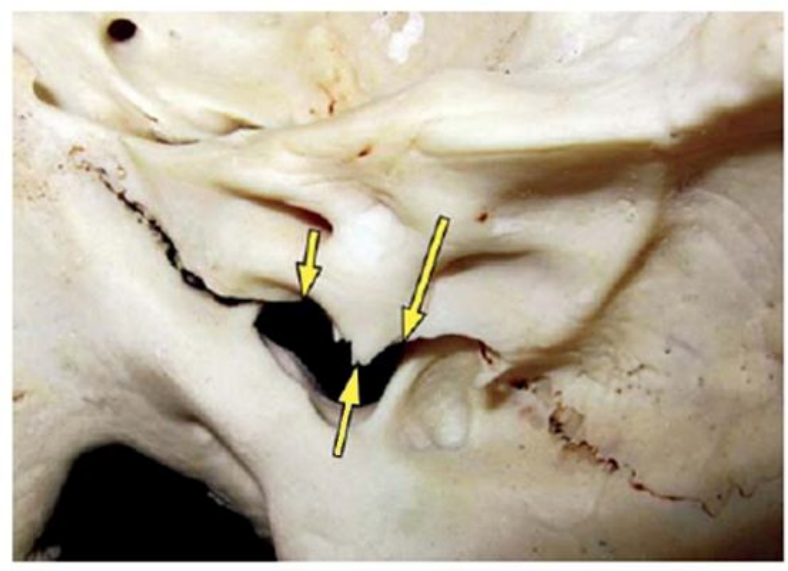

The jugular foramen studied in 50 adult human skulls and the present study revealed the following observations.

The anteroposterior diameter of the right jugular foramen measured in 50 skulls ranged between $8 \mathrm{~mm}$ to $19 \mathrm{~mm}$ with a mean of $12.11 \mathrm{~mm}$ . On the left side it ranged from $8 \mathrm{~mm}$ to $16 \mathrm{~mm}$ with a mean of $11.09 \mathrm{~mm}$. Overall mean was $11.06 \mathrm{~mm}$.

The mediolateral diameter of the right jugular foramen ranged from $10 \mathrm{~mm}$ to $20 \mathrm{~mm}$ with a mean of $15.04 \mathrm{~mm}$. On the left side it ranged from $18 \mathrm{~mm}$ to $19 \mathrm{~mm}$ with a mean of $14.02 \mathrm{~mm}$. Overall mean was $14.53 \mathrm{~mm}$.

Out of 50 skulls examined the right foramen was larger in 32 skulls and the left foramen was larger in 6 skulls and both the foramina were equal in size in 12 skulls.

Out of 50 foramina examined on the right side, septa were present in 17 skulls and absent in 5 skulls. On the left side out of 50 foramina examined septa was present in 15 skulls and absent in 7 skulls and in around 28 skulls it was absent bilaterally.

The right foramina showed complete septation in 9 skulls and incomplete septation in 8 skulls and in around 5 skulls septa is absent on right side only. In the left side, complete septa are observed in 9 skulls, in 6 skulls left foramen had incomplete septation and in 7 skulls septa is absent.

\section{DISCUSSION}

The shape and size of the jugular foramen is related to the size of the internal jugular vein and the presence or absence of a prominent superior bulb. Standard anatomical text books describes the superior sagittal sinus drains into the right transverse sinus, Thus right foramen is expected to be larger than the left [9]. But there is a very wide variation in the anatomy of the intracranial venous sinuses [10].

Anteroposterior Diameter of Jugular Foramen: The present study is comparable with the following studies: According to O. E. Idowu (2004) [11] in his study of 20 adult male Nigerian dry skulls reported that mean anteroposterior diameter was $10.22 \mathrm{~mm}(6.8-14.4 \mathrm{~mm})$ on the right side and $9.57 \mathrm{~mm}(7.4-12$. left $8 \mathrm{~mm})$ on left side. Slobodan Vlajkovic (2010) [12] in his study of 30 skulls of Serbian adults reported that mean anteroposterior diameter was 11.56 \pm 4 . Pereira et al (2010) [1] in his study of $111 d r y$ skulls of adult individuals in southern Brazil, with 31 female skulls and 80 male skulls reported that anteroposterior measurement of the jugular foramen, right side and left side in male skulls were $9.33 \pm 2.03 \mathrm{~mm}$ and $8.65 \pm 1.70 \mathrm{~mm}$ respectively. In the female skulls it was found to be $8.92+1.72 \mathrm{~mm}$ on the right side and $8.65 \pm 1.19$ on the left side.

In the present study the mean anteroposterior diameter was $12.11 \mathrm{~mm}$ on right side and $11.09 \mathrm{~mm}$ on left side.

Compared to the present study the value of anteroposterior diameter are very near to the findings given by Slobodan Vlajkovic.

The measurements of anteropostero diameter of the jugular foramen on the right side is comparable with the value given by 0 . E. Idowu and Pereira et al. It was significantly larger on the right side which may be related to prominent superior bulb of internal jugular vein.

Mediolateral Diameter of Jugular Foramen: According to O. E. Idowu (2004) [11] reported that mean mediolateral diameter was $13.90 \mathrm{~mm}$ $(11.6-17.0 \mathrm{~mm})$ on the right side and $14.11 \mathrm{~mm}$ $(9.2-20.2 \mathrm{~mm})$ on the left side. Slobodan Vlajkovic (2010) [12] reported that mean mediolateral diameter was $14.21 \pm 4.58$ $(9.2$ - 18.7) $\mathrm{mm}$ on the right side and 13.24 $\pm 4.01(9.7-18.0)$. Pereira et al (2010) [1] reported that mediolateral measurement of the jugular foramen, right side and left side in male skulls were $16.18 \pm 2.72 \mathrm{~mm}$ and $16.14 \pm 2.77 \mathrm{~mm}$ 
respectively. In the female skulls it was found to be $14.89 \pm 2.34 \mathrm{~mm}$ on the right side and $15.13 \pm 2.16 \mathrm{~mm}$ on the left side.

Present study observed that the mean mediolateral diameter of right jugular foramen was $15.04 \mathrm{~mm}$ and $14.02 \mathrm{~mm}$ on the left side.

Compared with the present study the value of mediolateral diameter was closely related to the findings given by Slobodan Vlajkovic and higher in the study by Pereira et al.

The mediolateral diameter was found to be comparable with different races and its value is slightly larger than the anteroposterior diameter.

Comparison between the size of right and left foramina in same skull: R.R.Sturrock (1998) [13] in his study with 156 skulls the right foramen was larger in 68.6\%; and left foramen was larger in $23.1 \%$ of skulls and equal in size in $8.3 \%$ of skulls. Hatiboglu and Anil (1991) [14] in their study of 300 Anatolian skulls observed that in $61.6 \%$ the foramen was larger on the right and in $26 \%$ on the left, with the remainder being of almost equal size. KaibogakuZasshi (1997) [15] in his study of 70 Turkish skulls he observed that $61.4 \%$ of the cases right Jugular foreman was larger than the left. In $24.3 \%$ the left was larger and in $14.3 \%$ they were equal in size.

In the present study jugular foramina were larger on the right side in $63 \%$, larger on left side in $12 \%$ and equal in size in $25 \%$.

Irrespective of the races, the right jugular foramen is larger than the left $[11,13,14]$. The large superior sagittal sinus continues in succession as right transverse sinus, right sigmoid sinus, and the right internal jugular vein, and the smaller inferior sagittal sinus continues in succession as straight sinus, left transverse sinus, left sigmoid sinus and into left jugular vein. There is wide variation in the anatomy of intracranial venous sinuses.

Presence of septation in the foramen: $R . R$. Sturrock (1987) [13] in his study observed that the percentage of septation on right side was $4.5 \%$ and that on the left was $14.1 \%$. Hatiboglu and Anil (1991) [14]] in their study observed the percentage of septation on the right was $8.2 \%$ and on the left was $23.9 \%$. Kaibogaku Zasshi (1997) [15] in his study reported that septa was present in $20 \%$ of the skulls and remaining $80 \%$ lacked septation.

Present study observed that the septation on right side was $35 \%$ and on the left was $31 \%$. The incidence of septation is less in the previous studies when compared to the present study.

Nature of septation: R. R. Sturrock (1987) [13] reported that complete septation of jugular foramen was present on right side in $3.2 \%$ and left side in $3.2 \%$. Partial or incomplete septation on right side in $1.3 \%$ and on left side in $10.9 \%$. Hatiboglu and Anil (1992) [14] observed that complete septation of jugular foramen was present on right side in $5.6 \%$ and left side in $4.3 \%$. Partial or incomplete septation on right side in $2.6 \%$ and on left side in $19.6 \%$. Patel and Singel (2007) [16] observed that complete septation of jugular foramen was present on right side in $23 \%$ and left side in $17.6 \%$. Partial or incomplete septation on right side in $49.5 \%$ and on left side in $59.3 \%$.

Present study observed that complete septation of jugular foramen was present on right side in $17 \%$ and left side in $17 \%$. Partial or incomplete septation on right side in $17 \%$ and on left side in $12 \%$. When compared with previous studies the present study showed variations in septation in jugular foramina.

\section{CONCLUSION}

The knowledge of morphology and morphometry of the jugular foramen is important for neurosurgeons and radiologists dealing with space occupying lesions in jugular foramen. These findings can be helpful to predict the chance of preserving intact neurovascular structures during surgical interventions in order to achieve desired surgical outcomes and avoid complications.

\section{Conflicts of Interests: None}

\section{REFERENCES}

[1]. Pereira GA, Lopes PT, Santos AM . M orphometric aspects of the jugular foramen in dry skulls of adult individuals in Southern Brazil. Journal of M orphological Sciences. 2010;27:3-5.

[2]. Williams PI, Bannisterlh, Berry M m, Collins P, Dyson $M$, Dussek Je, Et Al. Gray's Anatomy. 38 th edition. Edinburg; Churchill Livingstone: 1995 p.567.

[3]. Vijisha P, Bilodi AK, Lokeshmaran Morphometric study of jugular foramen in Tamil Nadu region. National Journal of Clinical Anatomy. 2013;2:71-4. 
[4]. Ramina R, Maniglia Jj, Fernandes Yb Et Al: Jugular foramen tumors: diagnosisand treatment. Neurosurg Focus, 2004; 17(2): E5

[5]. Borba La, Araujo Jc, De Oliveira Jg, Filbo M g, M orso Ms, Tirapelli Lf Et Al. Surgical management of glomus jugular tumours. A proposal for approach selection based on tumour relationships with facial nerve. J Neurosurg 2010;112(1):88-98.

[6]. Gjuric M, Bilic M. Transma stoidln fralabyri nthine Tailored surgery of jugular Paragangliomas. Skull base 2009;19(1):75-82.

[7]. Ladzinski P, M aliszewski M, Kaspera W, Szczygiel M, Tymowski M, Approach to the jugular foramen and related structures - an analysis of the surgical technique based on cadaver stimulation. Neurol Neurochir Pol 2011;45(3):260-74.

[8]. Sanna M, Bacciu A, Falcioni M, Taibali A. Surgical management of jugular foramen schwannomas with hearing and facial nerve preservation. A series of 23 cases and review of literature. Laryngoscope 2006;116(12):191-204.

[9]. Woodhall B. Anatomy of the cranial blood sinuses withparticular reference to the lateral. Laryngoscope 1939;49:966-1010.

[10]. Padget Dh. The development of the cranial venous system in man, from the viewpoint of comparative anatomy. Contributions to Embryology 1957;36:79140.

[11]. Idowu OE. The jugular foramen - A morphometric study. Folia Morphol (Warsz) 2004;63:419-22.

[12]. Slobodan Vlajkovic, Ljilana Vasovic, M arija Dakovic, Sasa Stankovic. Human bony jugular foramen : some additional morphological and morphometric features. Med SciM onit, 2010;16(5).
[13]. Sturrock R.R, Variations in the structure of the jugular foramen of the human skull. Journal of Anatomy. 1998; 160:227-230.

[14]. Hatiboglu, M. T. \& Anil, A. Structural variations in the jugular foramen of the human skull. J. Anat., 1992;180(1):191-6.

[15]. Kaibogaku Zasshi. Differences between traditional education and research in clinical anatomy conducted by anatomical departments and surgical training defined by the guidelines for cadaver dissection in education and research of clinical medicine. Journal of Anatomy 1997;72(6):525-529.

[16]. Patel \& Singel. Variations in the structure of jugular foramen of the human skull in Saurashtra Region. J. Anat. Soc. India. 2007;56(2):34-37.

\section{How to cite this article:}

M. Anuradha, S. Chitra. A STUDY OF THE MORPHOLOGY AND M ORPHOM ETRY OF THE JUGULAR FORAM EN OF THE HUM AN DRY SKULLS. Int J Anat Res 2017;5(2.3):3938-3942. DOI: 10.16965/ijar.2017.224 